\title{
DESIGN OF MODERN HYDRAULIC TANK USING FLUID FLOW SIMULATION
}

\author{
Tič, V., ${ }^{* * *} \&$ Lovrec, D. ${ }^{* *}$ \\ *OLMA d.d., Poljska pot 2, SI-1000 Ljubljana, Slovenia \\ ** University of Maribor, Faculty of Mechanical Engineering, Smetanova 17, SI-2000 Maribor, Slovenia \\ E-Mail: vito.tic@olma.si, d.lovrec@uni-mb.si
}

\begin{abstract}
Hydraulic power units are one of the most commonly used power sources in industry. The progress in recent years has offered high efficiency and reliable hydraulic components, yet the hydraulic tank design is often neglected part of the development.

The paper presents the development of industrial 400 litre hydraulic tank. In order to reduce oil swirling and improve stability of fluid flow, CFD simulations of oil flow inside hydraulic tank were made. Several variations of new hydraulic tank designs are compared with standard industrial tank. Furthermore, to achieve steady flow through the entire reservoir and reduce the phenomenon of oil swirling, newly-developed diffuser is used. Consequently a full scale hydraulic power unit was built according to obtained results.

(Received in September 2011, accepted in February 2012. This paper was with the authors 1 month for 1 revision.)
\end{abstract}

Key Words: Hydraulic Tank, Fluid Flow, Simulation, Design

\section{INTRODUCTION}

Hydraulic power units are types of equipment, from which the user expects an energy-saving and reliable operation with minimum maintenance problems, even in cases when operated within a basic industrial environment. The potential consequences for the user of any bad decisions made during its design can be a lifetime of high operating and maintenance costs.

At the same time, hydraulic power units represent those parts of hardware which operate within different types of technology: mechanical engineering, electricity, electronics, informatics, and sensorics. Denying or ignoring one of those elements at any time leads to the already mentioned lack of functioning by the entire system. In its development, there is an urgent need to take into account all the specific knowledge from these areas of technology.

The design of an appropriate hydraulic power unit follows the development of a hydraulic tank as one of the major building blocks, which is primarily intended for the storage of liquid, and maintaining its properties. The creation of a hydraulic tank definitely needs greater attention, as its correct design has an influence on the operation of the entire hydraulic system. Most common mistakes made during tank design, are only seen during its operation over time, and can cause many problems for users and maintenance personnel. It is necessary to pay special attention thus trying eliminating air and condensate, and at the same time, identifying flow-patterns in the tank and thus trying to stabilize the liquid $[1,2]$.

The help of virtual engineering can be used, when designing a modern hydraulic tank. Hydraulic components and devices are typically parts of the control and drive systems. Due to their inherent transient operating conditions, and the transformation of fluid flow into the mechanical movement they pose a challenge for virtual engineering. Unsteady fluid-flow, movement and deformation within the simulation domain, and physical phenomenon such as cavitation, place great demands on the simulation tools [3]. 
Available computational power has increased considerably and more capable simulation tools for complex physics are now available. During the process of design and development, the demands on robust and reliable products have to be considered together with multiple design restrictions parameters of influence. All these aspects can only be fulfilled by the integration of CAD and CFD tools [3].

The advantage of using simulation techniques in the field of hydraulic tank design will be explained by illustrating the results of on-going research tasks.

\section{FUNCTIONS OF A HYDRAULIC TANK}

A hydraulic tank is an important part of a hydraulic power unit and represents the heart of the hydraulic system. It needs to perform several functions, among which the most are summarized below.

\subsection{Primary function}

The primary function of any tank is the storage of substances or fluids. In our case, the tank must retain the total quantity of hydraulic oil, which is located in the hydraulic system. In addition the hydraulic tank should compensate for oil level oscillation due to temperature changes or possible leakage from the system.

\subsection{Cooling of hydraulic fluid}

As a result of losses arising from the transformation of energy in the hydraulic components, the temperature of the hydraulic fluid rises when passing through the system. In addition to an additional cooling system, the tank itself also emits a large proportion of heat through the surfaces in the surrounding area. The radiated power of heat primarily depends on the sizes of those areas in contact with the surroundings, and the temperature difference between the hydraulic oil and the surrounding area. When designing the hydraulic tank, a designer should properly form the tank in order to increase the size of the area through which heat is emitted thus providing better natural cooling (cooling ribs).

\subsection{Elimination of air}

One of the long-term risks of the hydraulic system is the formation of air bubbles, which can be detected by the noisy operation of components. They usually occur at pressures below the saturation pressure, leakage points on the system, or by an excessive swirl of oil at the return line. A hydraulic tank should be designed to provide optimum air extraction from the oil. The usual consequences are:

- destruction of pumps due to the emergence of cavitation on the inlet side,

- imprecise movements caused by increased fluid compressibility,

- temperature increase of oil,

- accelerated aging of oil,

- accelerated destruction of seals.

\subsection{Elimination of condensate}

Condensation is a result of temperature changes in tank's hydraulic fluid. Any non-binding water in the oil has an adverse impact on the hydraulic system, as it accelerates the corrosion of metal parts, reduces the lubricating properties, and causes rapid aging of the oil. The minimum proportion of water is bound with the oil, resulting in the formation of emulsion. 
This residue is excreted as loose water which is, in the case of slow-flows, retained in the lowest part of the tank (water has a higher density than hydraulic oil).

\subsection{Disposing of dirt}

All the dirt cannot be removed by fine filtration. After a long operating period they accumulate at the bottom of the tank. A designer must provide for the pumping of clean oil by using the proper installation of suction and return tubes. This practice seeks to avoid this problem by cutting off the ends of flow tubes at an angle of approximately $45^{\circ}$ (turned away from each other), thus providing a smaller interactive effect. This problem can also be solved with the use of an additional wall, separating the suction and return sections of the tank.

\subsection{Other functions}

During the life-cycle of a hydraulic power unit, maintenance interventions are carried out, thus the tank must be designed to facilitate maintenance. It should be possible to access individually built-in components. Therefore the tank should have several cleaning openings for accessing the inside of the tank, through which it can be examined and cleaned.

Finally, vibration and sound should be kept to a minimum. Modern designed components are often already optimized by the manufacturer, and produce much less noise than components of older generations.

\section{USE OF VIRTUAL ENGINEERING IN HYDRAULICS}

Simulation techniques are becoming more and more established during the design and development processes regarding new products [4, 5]. Driven by developments in high technology industries such as aerospace and automotive also use these methods for estimating robustness and reliability. They also represent an important part of innovation processes [6].

Hydraulics, as more traditional parts of mechanical engineering, is produced by small and middle range companies. They are mostly suppliers of machine tools manufacturers, the process engineering and automotive industries. Over the past decade, there has been a trend backwards from delivering single components to the design of assemblies or complete functional units. An additional trend is the change from fluidic components only to complex mechatronic systems, including units for signal conditioning, electromechanical actuators, controller electronics, and sensors. Interaction between components and sub-assemblies are no longer negligible. Within the engineering aura, hydraulics and pneumatics have dramatically changed and become more complex and multidisciplinary. The operational conditions for hydraulic and pneumatic systems pose a challenge for virtual engineering [3].

In hydraulics, you have to deal with some extremely nonlinear effects: Many flow processes are within transition ranges, e.g. from laminar to turbulent. In hydraulics we have cavitation and aeration at low pressure. Therefore multi-phase models have to be developed, and additional material data needed. These topics will become increasingly important due to certain on-going trends like:

- miniaturisation and functional integration of components and systems,

- needs for energy consumption and noise reduction,

- increasing demands in regard to more reliable, robust, and safe products.

These all result in a discrepancy between the complexity of physics and the modelling of real operational conditions in hydraulics on the one hand, and the limited capacity in research and development of mainly small companies in the fluid power industry, on the other hand. 
To date there are several known researches (simulations) of fluid flow, and optimization studies in hydraulic components and tubing. Unfortunately, none of them involve fluid-flow simulations in a hydraulic tank.

When designing a hydraulic tank, the exact flow situation within the tank needs to be known. When constructing a modern hydraulic power unit, fluid flow can be simulated to help form a better tank, and an optimum layout of the components. Modelling and numerical simulation tools with correct choices of parameters and boundary conditions provide an excellent approximation of the current situation in the interior of the tank.

\section{MODELS AND SIMULATIONS}

\subsection{Tank design model}

A model of a hydraulic tank was developed in Catia V5, one of the most powerful and widely-used CAD software. It is based on a 400 litre tank according to "AB Normen Rexroth" (DN 400) [7], with inner dimensions of $1492 \times 712 \times 390 \mathrm{~mm}$.
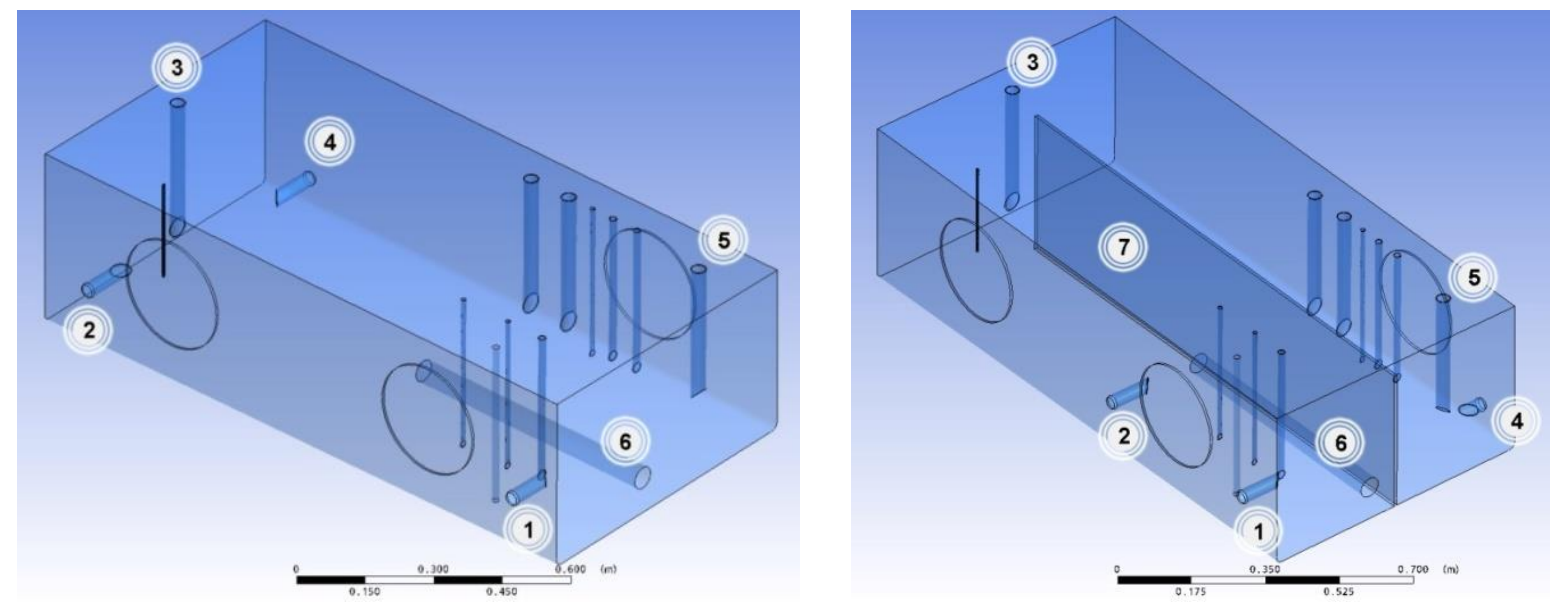

Figure 1: First (left) and second (right) model of hydraulic tank in Catia.

As shown in Fig. 1, there were two different models designed (continued as first and second models), and they consist of:

- main suction tube feeding $1^{\text {st }}$ pump (1),

- main suction tube feeding $2^{\text {nd }}$ pump (2),

- bypass cooling-filtering return tube (3),

- bypass cooling-filtering suction tube (4),

- main return tube (5),

- heater (6),

- partition wall (7),

- other tubes and restricting objects.

In addition, a third model was designed, which is basically the same as the second model. The only difference between them is the diffuser, which we developed during our research, and is mounted on the return filter (instead of return tube). The diffusers geometry was optimized according to the size of the tank and the flow-capacity of the pump. As shown in Fig. 2, it is made of a hydraulic tube (31 mm inner diameter), which has one end closed by welding sheet metal onto it. This particular diffuser has 24 holes with $8 \mathrm{~mm}$ diameter, to ensure sufficient flow. This gives us flow area of $1206 \mathrm{~mm}^{2}$, compared with $755 \mathrm{~mm}^{2}$ on a regular tube. The surrounding circles are used for flow direction. 

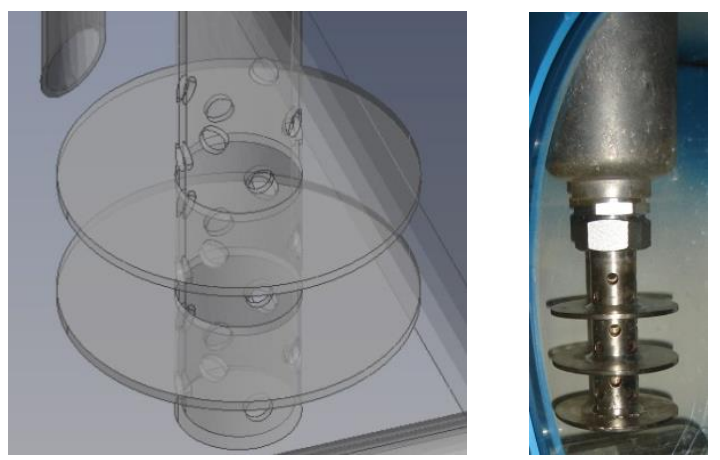

Figure 2: Model of developed diffuser used in third model (left) and its application (right).

\subsection{Mesh generation}

Numerical simulation for the flow inside hydraulic tank was performed in Ansys Workbench V11. The numerical code is based on the finite-volumes method (FVM). The calculation area is a 3D volume, closed from all sides. The area is divided into tetrahedrons. Such a tetrahedron is called a flow-element, and its edges represent the calculating nodes. This type of mesh is an non-structured mesh. The location of the nodes is determined by the Cartesian coordinates $x, y$, and $z$. The dependent variables of pressure, velocity, turbulent kinetic energy, dissipation of the turbulent kinetic energy and the volume fraction are calculated for each node of the flow-element [8].

Surface and volume mesh were automatically created in Ansys CFX-Mesh with regard to additional settings. The advancing front and inflation 3D meshing strategy was used with a combination of advancing front volume meshing. The mesh was refined near the tubes and restrictive objects to obtain more realistic results. Base angular resolution was set at $18^{\circ}$.

Near solid walls boundary layers affect velocity gradients, which are maximal in the normal direction on wall. Thus, five inflation layers were created around the tubing with an expansion factor of 1.2 - 1.5 depending on tube's diameter, shown in Fig. 3 (right).

The mesh results are presented in Table I and shown in Fig. 3.

Table I: Mesh data.

\begin{tabular}{|l|c|c|}
\hline \multicolumn{1}{|c|}{ Model } & Nodes & Elements \\
\hline First model & 435,975 & $1,634,906$ \\
\hline Second model & 289,470 & $1,368,676$ \\
\hline Third model & 403,931 & $1,868,643$ \\
\hline
\end{tabular}
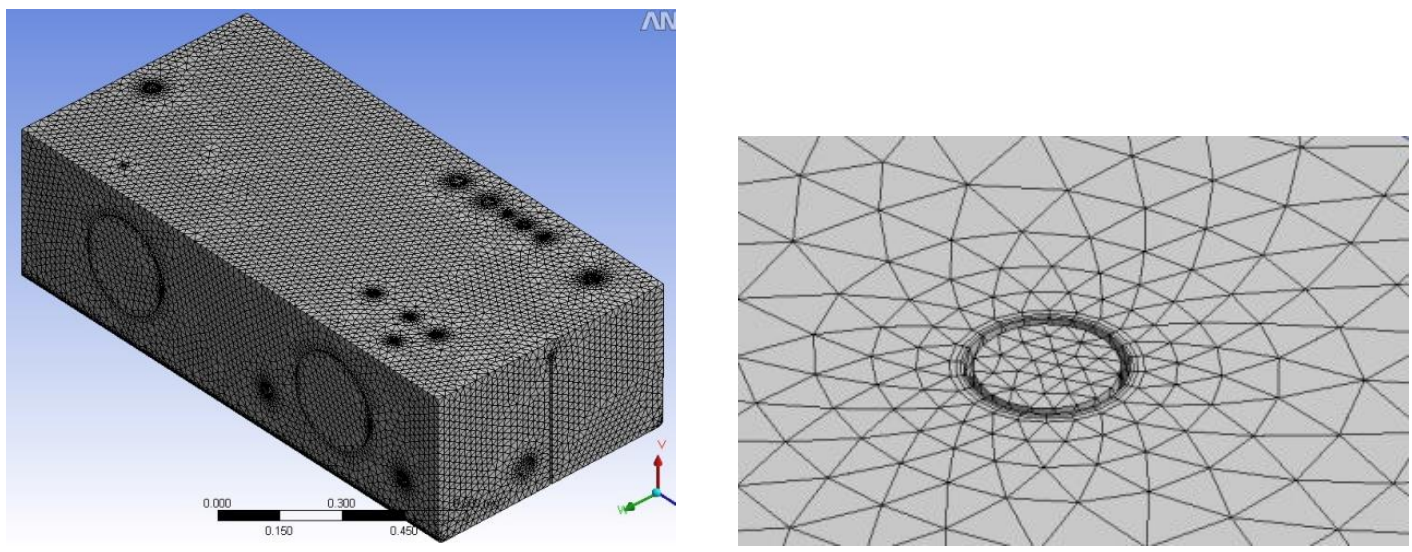

Figure 3: Mesh of the first model (left) and close-up of creating inflating layers. 


\subsection{Simulation model and parameters}

Un-steady (transient) simulations are generally used because of the dynamic operation of hydraulics. A basic industrial hydraulic power unit commonly consists of a fixed displacement gear-pump, which is powered by an electric motor with constant turning speed. When there is no energy consumption on the actuators, the oil is simply returned into the tank through a bypass valve. We can assume that the mass flow rate at the inlet is almost stable. At the time of this particular research, we decided to neglect the fluctuation of mass flow rate through the return tube (system inlet), and use steady-state simulation instead.

Multiphase simulation involves two homogenous materials - air and standard mineral hydraulic oil (ISO VG46), with properties, as shown in Table II. The thermodynamic state and molar mass of a fluid plays an important role while simulating fluid flow. For fluids in liquid state density [9] and viscosity are important factors as well.

Table II: Material properties.

\begin{tabular}{|l|c|c|}
\hline & Air & ISO VG46 \\
\hline Thermodynamic state & Gas & Liquid \\
\hline Molar mass $[\mathrm{kg} / \mathrm{kmol}]$ & 28.96 & 300 \\
\hline Density $\left[\mathrm{kg} / \mathrm{m}^{3}\right]$ & 1.185 & 880 \\
\hline Viscosity $[\mathrm{cSt}]$ & - & 46 \\
\hline Specific heat capacity $[\mathrm{J} / \mathrm{kg} \cdot \mathrm{K}]$ & 1004.4 & 1966 \\
\hline Ref temperature $\left[{ }^{\circ} \mathrm{C}\right]$ & 25 & 40 \\
\hline Reference pressure $\left[\mathrm{N} / \mathrm{mm}^{2}\right]$ & $1 \cdot 10^{5}$ & $1 \cdot 10^{5}$ \\
\hline
\end{tabular}

Information about the boundary layers of the calculating domain is defined by the following boundary conditions:

- wall condition,

- inlets condition,

- outlets condition.

No flow-slip on the wall is considered with wall roughness of $0.05 \mathrm{~mm}$. Bulk mass flow rate is defined at the inlet (return tube) and at the outlet (suction pipes) of the system, as described in Table III.

Table III: Boundary conditions.

\begin{tabular}{|l|c|c|}
\hline & $\begin{array}{c}\text { Bulk mass flow rate } \\
{\left[\mathrm{kg} / \mathrm{m}^{3}\right]}\end{array}$ & $\begin{array}{c}\text { Approx. volume flow rate } \\
{[1 / \mathrm{min}]}\end{array}$ \\
\hline Inlet (5) & 0.6 & 40.91 \\
\hline Outlet (1) & 0.6 & 40.91 \\
\hline
\end{tabular}

\subsection{Homogenous two phase flow model}

The presented homogenous two-phase flow model is based on the equations described, as outlined in the following $[8,10,11]$.

The mass continuity equation (1) results from the fundamental physical principle that mass is conserved. In integral form it can be written as:

$$
\frac{\partial}{\partial t} \int_{V} \rho d V+\int_{S} \rho v_{j} n_{j} d S=0
$$


The resulting force on the volume element is equal to the time increment of the momentum in the volume, and the flux across the element's surface. The momentum equation (2) in integral form can be written as:

$$
\int_{V} \frac{\partial \rho v_{i}}{\partial t} d V+\int_{S} v_{i} \rho v_{j} n_{j} d S=\int_{V} \rho f_{i} d V+\int_{S}\left(-p \sigma_{i j}+\tau_{i j}\right) n_{j} d S
$$

where $v_{i}$ is the velocity flow field, $f_{i}$ is the body force, $p$ is the thermodynamic pressure, and $\tau_{i j}$ is the shear stress.

The two-equation model for turbulent kinetic energy $k$ and the dissipation of turbulent kinetic energy $\varepsilon$, or the $k-\varepsilon$ model, is the most important two-equation turbulent model based on the turbulent viscosity principle. The turbulent stresses $-\rho_{0} v_{i} \widetilde{v}_{j}^{\prime}$ are expressed using the Boussinesque approximation, as follows:

$$
\left(-\rho_{0} v_{i}^{\prime} v_{j}^{\prime}\right)=\rho_{0} v_{T}\left(\frac{\partial \tilde{v}_{i}}{\partial x_{j}}+\frac{\partial \tilde{v}_{j}}{\partial x_{i}}\right)-\frac{2}{3} \sigma_{i j} \rho_{0} k
$$

where $k$ is the averaged kinetic energy of the turbulent fluctuations, and $v_{T}=\left(\eta_{T} / \rho\right)$ the turbulent viscosity. The factor $2 \delta_{i j} k / 3$ is an extension of the Boussinesque hypothesis that can be added to the static pressure.

The characteristic properties are defined using the characteristic velocity:

$$
\hat{u}=\sqrt{k}
$$

and the dissipation velocity of the turbulent kinetic energy $\varepsilon$ :

$$
\varepsilon=v_{0} \frac{\partial v_{i}^{\prime} \tilde{\partial} v_{i}^{\prime}}{\partial x_{j} \partial x_{j}}
$$

which defines the conversion of the turbulent energy into heat. Both quantities $k$ and $\varepsilon$ are determined from additional, specific differential equations (6) and (7), which include new constants and functions. For $k$ the following equation is valid:

$$
\frac{\partial k}{\partial t}+\tilde{v}_{i} \frac{\partial k}{\partial x_{i}}=\frac{\partial}{\partial x_{i}}\left[\left(v_{0}+\frac{v_{T}}{\sigma_{k}}\right) \frac{\partial k}{\partial x_{i}}\right]+P-\varepsilon
$$

and similarly for $\varepsilon$ :

$$
\frac{\partial e}{\partial t}+\tilde{v}_{i} \frac{\partial e}{\partial x_{i}}=\frac{\partial}{\partial x_{i}}\left[\left(v_{0}+\frac{v_{T}}{\sigma_{e}}\right) \frac{\partial e}{\partial x_{i}}\right]+C_{1 \varepsilon} \frac{\varepsilon}{k} P-C_{2 \varepsilon} \frac{\varepsilon^{2}}{k}
$$

where the standard values of the constants are: $\sigma_{k}=1.0, \sigma_{e}=1.3, C_{1 \varepsilon}=1.44$ and $C_{2 \varepsilon}=1.92$.

Volume fraction is calculated using additional expressions, which are manually added to the system. It is assumed that two phases, air and the oil, are always separated and their interaction can be described by the hydrostatic pressure equation:

$$
p_{s t}=p_{a t m}+\rho g h
$$

Eq. (8) is also known as Pascal's Law and is implemented into the model in order to initialize the domain and establish a two phase model with oil height of $340 \mathrm{~mm}$.

\subsection{Numerical solving}

The time step of the simulation was chosen automatically, with a convergence target of $1 \cdot 10^{-6}$. As this convergence is hard to achieve, a maximum of 300 iterations was set. 
Calculation time varied from 8 to 9 hours. Actual convergence numbers from the simulation results are shown in Table IV.

Table IV: Simulation convergence.

\begin{tabular}{|c|c|}
\hline & RMS Residuals \\
\hline U-Mom-Bulk & $<1 \cdot 10^{-5}$ \\
\hline V-Mom-Bulk & $<1 \cdot 10^{-5}$ \\
\hline W-Mom-Bulk & $<1 \cdot 10^{-5}$ \\
\hline Mass-Air & $\approx 1.3 \cdot 10^{-5}$ \\
\hline Mass-VG46 & $<1 \cdot 10^{-5}$ \\
\hline K-TurbKE-Bulk & $<1 \cdot 10^{-5}$ \\
\hline E-Diss.K-Bulk & $<1 \cdot 10^{-5}$ \\
\hline
\end{tabular}

\section{RESULTS}

Simulation results are presented as 3D streamlines in Figs. 4 and 5. In the first model, fluid flows towards the bottom of the tank, where it is reflected. A high proportion of this flow is immediately sucked-up by the pump, generating a short circuit between the return and suction tubes. The second model shows the same pattern of fluid flow at the return tube, while directing the flow around the wall before being sucked-up by the pump. This gives valuable time for the fluid to cool down, extract impurities at the bottom, and lift any air bubbles of oil. Although the flow is directed at most parts, there is a highly stirred area around the return tube of the system, causing dirt to be lifted.
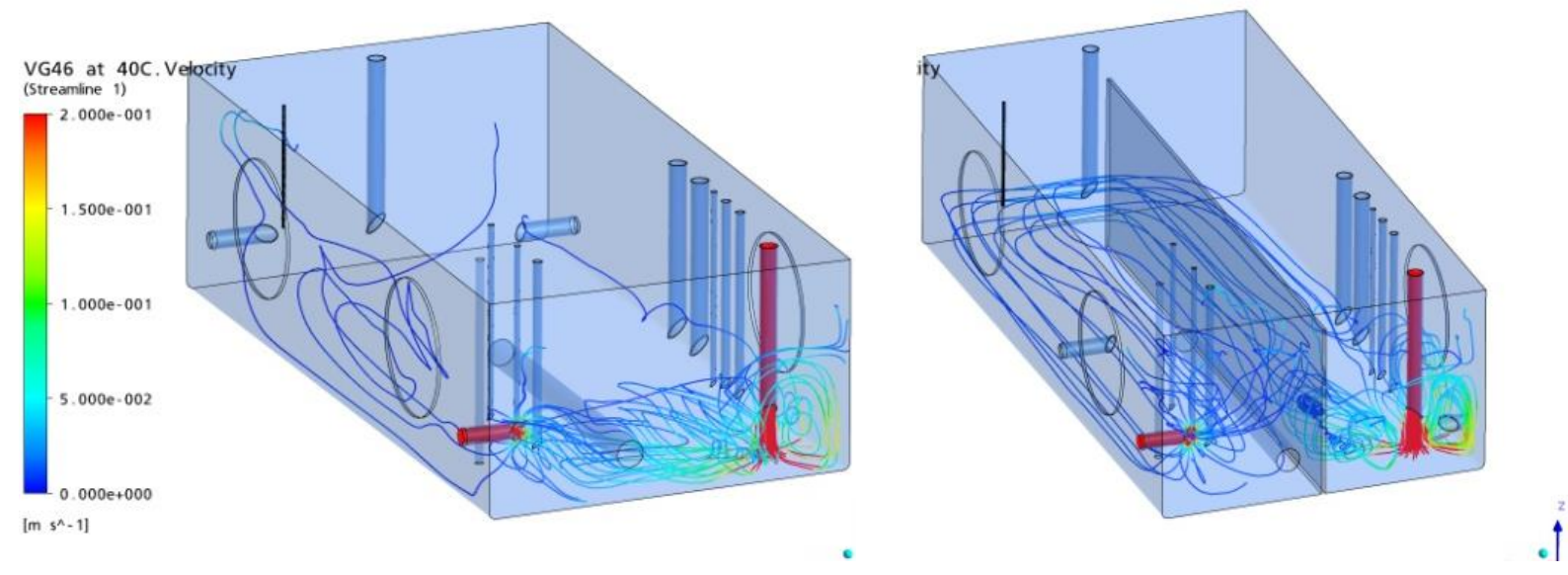

Figure 4: 3D streamlines in the first (left) and in the second (right) model.

Far more better is the third model with the newly-developed diffuser on the return tube, shown in Fig. 5. As oil flows through horizontal openings of the diffuser, it is immediately directed and slowed down, causing a much more stabilized fluid flow, which allows the fluid to regain its properties - temperature, cleanliness, elimination of air bubbles. 


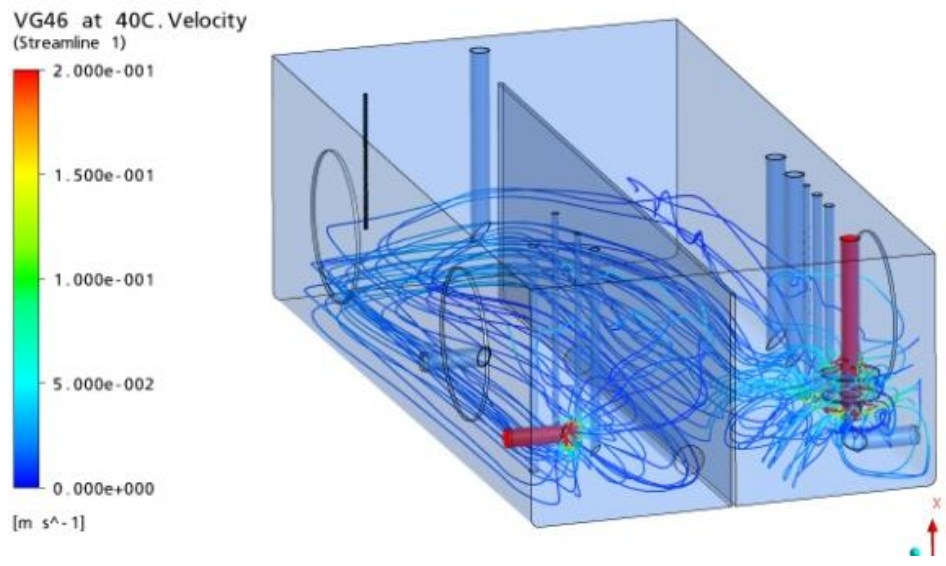

Figure 5: 3D streamlines in the third model.

For better result review, they are also presented in the form of absolute velocity on a horizontal plane at a height of $40 \mathrm{~mm}$, in Fig. 6. The results show that the third model significantly reduces flow impact on the bottom layer of the tank.
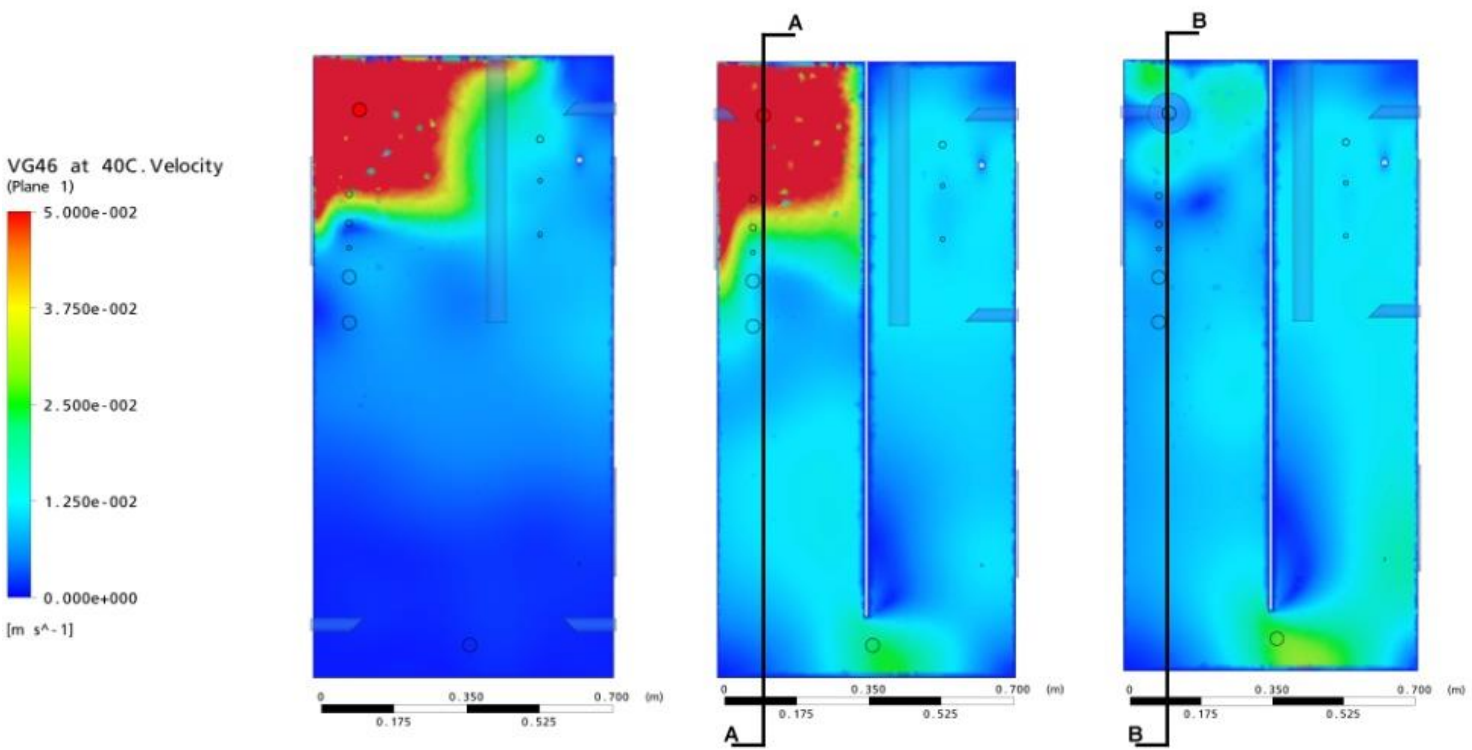

Figure 6: Oil velocity at $h=40 \mathrm{~mm}$; from left to right: first, second and third model.

The phenomenon of swirling is also represented in Fig. 7 in the form of planar streamlines for the second (cutting plane A-A), and the third model (cutting plane B-B). Figure shows high intensity swirling in the second model, where the fluid reaches the bottom of the tank. With the use of a diffuser in the third model in the swirling is significantly reduced.
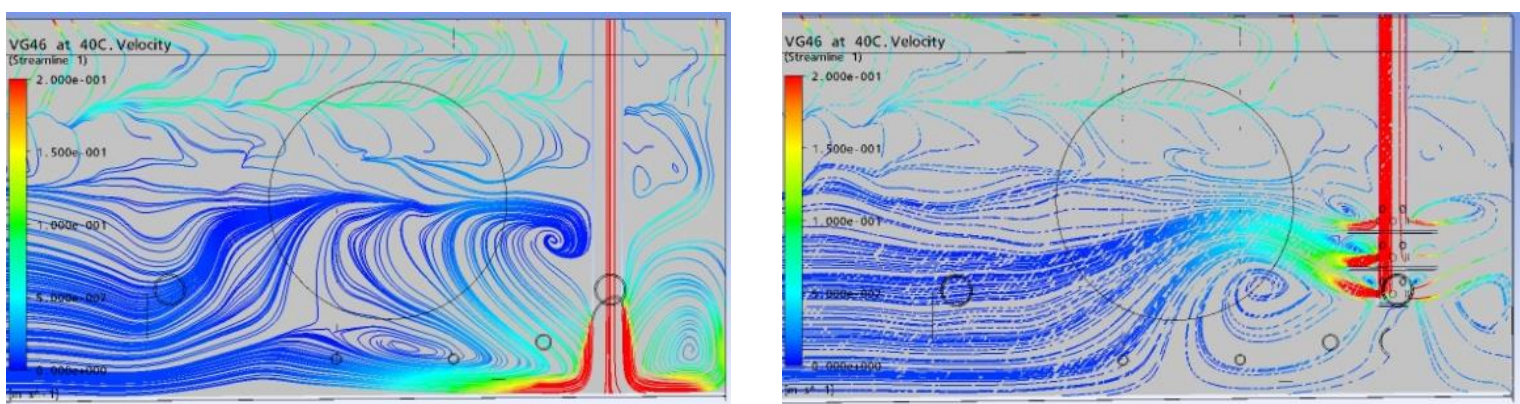

Figure 7: 2D streamlines in the second (A-A) and in the third (B-B) model. 


\section{DISCUSSION}

Efficient software modelling and simulation tools offer us an important series of options and views for simulation results. Several more streamline models and cutting planes were studied during the research, including velocity vectors and turbulent kinetic energy. Unfortunately, all of them cannot be shown, although they were also studied and considered when designing a new tank design with a partition-wall and a diffuser mounted on the return tube (third model). There were also many more models and simulations made. Only the most representative are shown.

After studying simulation results, the actual tank was built according to the third model, which shows:

- It is reasonable to use a partition-wall, as a simple and cheap measure that intensely directs and stabilizes oil flow.

- Partitions should be longitudinal, as they provide greater calming of the oil.

- Partitions should be two, at most three. In a stationary tank, a larger number of partitions would be pointless.

- Use of more than three partitions results in more stationary fluid regions, which are undesirable.

- Use of the newly-developed diffuser greatly reduces oil swirling and significantly helps stabilize fluid flow.

Fig. 8. presents the constructed hydraulic tank with several openings made of plexus glass, which will allow us to observe oil flow when determining the accuracy of the simulation results.
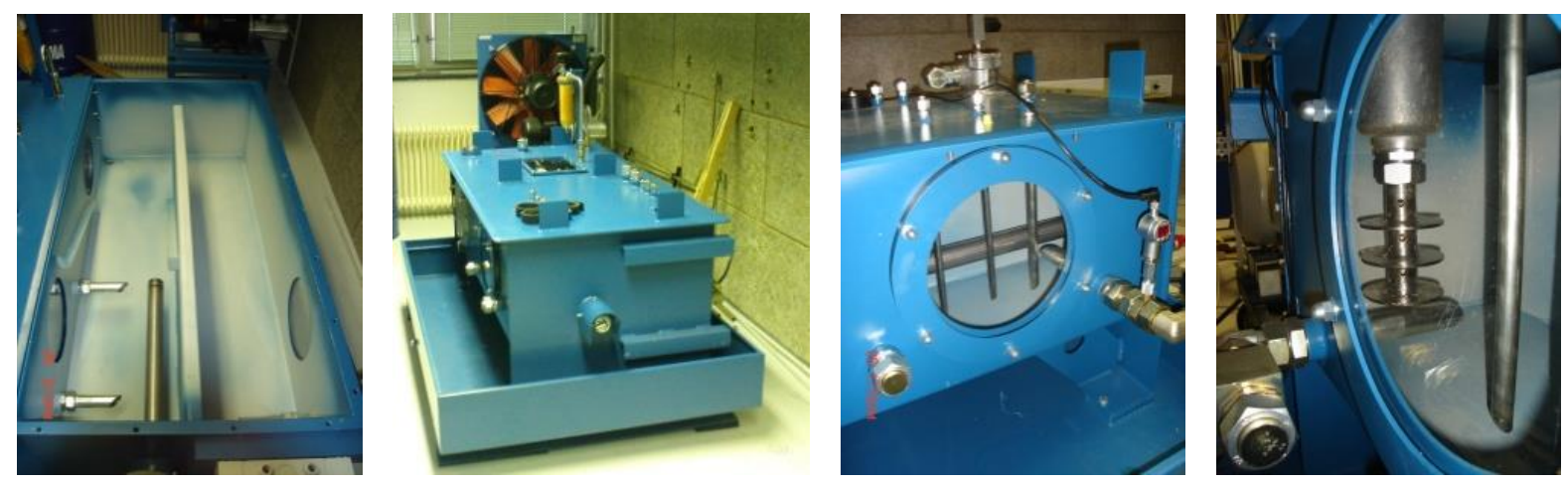

Figure 8: New tank according to the third model.

\section{CONCLUSION}

Use of CFD simulation tools helps us to understand fluid flow in a stationary hydraulic tank. The represented results were used to develop and construct a new form of hydraulic tank. The model that was developed can be further used for oil flow analysis in more complex simulations. Since this research is in its infancy and only steady-state simulations were studied, we will continue our research implementing heat transfer models along with a bypass cooling system being taken into account. One of the next steps in our research will certainly be the use of transient simulation where we will be able to study transient results of different phenomena in the hydraulic tank, e.g. back-surge from discharging the hydraulic reservoir.

Overlooking the results presented in the paper it can be seen that the use of fluid flow simulation is preferred or even "a must" while designing a modern hydraulic tank. We showed that small cost-effective modifications can make a great difference on hydraulic unit 
long-term operation, reliability and maintenance costs. And although our simulation model is based on a stationary hydraulic power unit, we believe that research results would be even more interesting in the field of mobile hydraulics tanks.

\section{ACKNOWLEDGEMENT}

Operation part - financed by the European Union, European Social Fund. Operation implemented in the framework of the Operational Programme for Human Resources Development for the Period 2007-2013, Priority axis 1: Promoting entrepreneurship and adaptability, Main type of activity 1.1.: Experts and researchers for competitive enterprises.
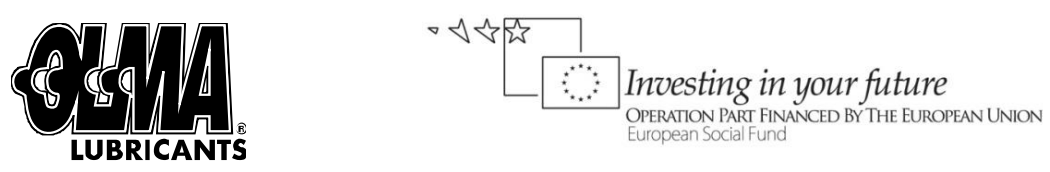

\section{SYMBOLS}

$C_{1 \varepsilon} \quad$ constant

$C_{2 \varepsilon} \quad$ constant

$f_{i} \quad$ body force

$g$ gravitational acceleration

$h$ height of liquid

$k \quad$ turbulent kinetic energy

$n_{j} \quad$ surface normal

$P \quad$ turbulent kinetic energy production

$p \quad$ thermodynamic pressure

$p_{s t} \quad$ hydrostatic pressure

$p_{\text {atm }} \quad$ atmosphere pressure

$S \quad$ surface of control volume

$t$ time

$\hat{u} \quad$ characteristic velocity

$\widetilde{v}_{2} \quad$ time averaged velocity vector

$V \quad$ control volume

$\delta_{i j} \quad$ Kronecker delta function

$\varepsilon \quad$ disipation velocity of turbulent kinetic energy

$v_{0} \quad$ kinematic viscosity

$v_{T} \quad$ turbulent kinematic viscosity

$\rho$ density

$\sigma_{i j} \quad$ stress tensor

$\tau_{i j} \quad$ shear stress tensor

\section{REFERENCES}

[1] Bruns, H.; Timmers, A. (1997). Hydraulikbehälter: Mehr als nur ein Tank, $O+P$ Ölhydraulik und Pneumatik, Vol. 41, No. 9

[2] Lovrec, D.; Kambič, M. (2007). Hidravlične tekočine in njihova nega, University of Maribor, Faculty of Mechanical Engineering, Maribor

[3] Rüdiger, F. (2007). Virtual engineering of hydraulic and pneumatic components and systems, Proceedings of Fluid power 2007, Maribor, Slovenia, 1-4 
[4] Novak-Marcincin, J.; Brazda, P.; Janak, M.; Kocisko, M. (2011). Application of virtual reality technology in simulation of automated workplaces, Technical Gazette, Vol. 18, No. 4, 577-580

[5] Hammadi, M.; Choley, J. Y.; Penas, O.; Louati, J.; Rivière, A.; Haddar, M. (2011). Layout Optimization of Power Modules Using a Sequentially Coupled Approach, International Journal of Simulation Modelling, Vol. 10, No. 3, 122-132, doi:10.2507/IJSIMM10(3)2.183

[6] Palcic, I.; Buchmeister, B.; Polajnar, A. (2010). Analysis of Innovation Concepts in Slovenian Manufacturing Companies, Strojniški vestnik - Journal of Mechanical Engineering, Vol. 56, No. $12,803-810$

[7] N.N. AB Normen Rexroth

[8] Biluš, I.; Škerget, L.; Predin, A.; Hriberšek, M. (2005). Experimental and numerical analyses of the cavitational flows around a hydrofoil, Strojniški vestnik - Journal of Mechanical Engineering, Vol. 51, No. 2, 103-118

[9] Banaszek, A.; Petrović, R. (2010). Calculations of the unloading operation in liquid cargo service with high density on modern product and chemical tankers equipped with hydraulic submerged cargo pumps, Strojniški vestnik - Journal of Mechanical Engineering, Vol. 56, No. 3, 186-194

[10] Škerget, L. (1994). Mehanika tekočin, University of Maribor, Faculty of Mechanical Engineering, Maribor

[11] Ansys. Ansys CFX Help, Release 11.0 